потребностью в антибактериальной терапии в среднем 2 [2; 3] раза в год. Полученные в работе результаты согласуются с литературными данными o более позднем дебюте неаллергической бронхиальной астмы, преобладании женщин среди больных НБА, преимущественно среднетяжелом и тяжелом течении заболевания с частыми и длительными обострениями, сочетанием с полипозным риносинуситом [9].

1) Заключение. Клинический фенотип аллергической бронхиальной астмы у взрослых в Ставропольском крае характеризуется дебютом в молодом возрасте (18 лет), преобладанием среднетяжелых форм $(58,4 \%)$, сенсибилизацией к пыльцевым $(55,4 \%)$ бытовым и эпидермальным $(7,7 \%)$ аллергенам, частым развитием сочетанной гиперчувствительности $(36,9 \%)$, эозинофильным $(65 \%)$ и малогранулоцитарным $(27,7 \%)$ типом воспаления в индуцированной мокроте.

2) Особенностью неаллергического фенотипа бронхиальной астмы является начало заболевания после 30 лет, преобладание женщин $(85,8 \%)$, частое развитие среднетяжелых $(28,6 \%)$ и тяжелых $(57,1 \%)$ форм бронхолегочного процесса, сочетание с хроническим полипозным риносинуситом (14,3\%), распространенная персистенция респираторных патогенов (74,2\%), развитие эозинофильного (34,3\%), нейтрофильного $(22,8 \%)$ и смешанного гранулоцитарного воспаления $(28,6 \%)$.

\section{Литература:}

1.Global Initiative for Asthma. Global Strategy for Asthma Management and Prevention (GINA). National Institutes of Health; National Heart, Lung, and Blood Institute. Up-dated 2014.http://www.ginasthma.org

2.Alexis N. E. Biomarker sampling of the airways in asthma // Curr. Opin. Pulm. Med, 2014, Vol. 20, №1, P. 46-52.

3.Хаитов Р. М. Аллергология и иммунология. / Р. М. Хаитов, Н. И. Ильина // Национальное руководство. - М.: ГЭОТАР-МЕДИА. - 2014. - С. 656.

4.Xie, M. A., Wenzel S. E. global perspective in asthma: from phenotype to endotype// Chinese medical journal, 2013, Vol. 126, № 1, P. 166-174.

5.Ненашева, Н. М. Фенотипы бронхиальной астмы и выбор терапии / Н. М. Ненашева // Практическая пульмонология. - 2014.- №2 - - С. 211 .

6.Bakakos P., Schleich F., Alchanatis M., Louis R. Induced sputum in asthma: from bench to bedside. Curr. Med. Chem., 2011, Vol. 18, №10, P. 1415-1422.

7.Уханова, О. П. Аэроаллергены: учебнометодическое пособие / О. П. Уханова, Е. В. Богомолова. - Новосибирск: Издательство ЦРНС. 2015. - C. 44.

8.Brooks C.R., Van Dalen C.J., Harding E., Hermans I.F., Douwes J. Effects of treatment changes on asthma phenotype prevalence and airway neutrophil function // BMC Pulm Med., 2017, Vol. 17, № 1, P.169.

9.Comi A.L., Tedeschi A., Lorini M., Miadonna A. Novel clinical and serological aspects in nonallergic asthma Respiratory Medicine, 2007, T.101, Vol. 12, P. 2526-2533.

\title{
УДК: 615.03
}

\section{ПРОФИЛЬ АНТИМИКОТИКОРЕЗИСТЕНТНОСТИ ИЗОЛЯТОВ РОДА САNDIDA ПРИ ИНФЕКЦИЯХ УРОГЕНИТАЛЬНОГО ТРАКТА}

\author{
${ }^{1}$ Каримов И.Ф., ${ }^{1}$ Домнина Н.А., ${ }^{2}$ Михайлова Е.А., ${ }^{3}$ Акжнигитов А.С. \\ ${ }^{I}$ ФГБОУ ВО «Оренбургский государственный университет» \\ ${ }^{2}$ ФББОУ ВО «Оренбургский государственный медицинский университет» \\ ${ }^{3} \mathrm{AHO} \mathrm{«Центр} \mathrm{инновачий} \mathrm{и} \mathrm{наукоемких} \mathrm{технологий»}$ \\ DOI: $\underline{10.31618 / \text { nas.2413-5291.2019.1.50.105 }}$
}

\section{Резюме}

В данной статье изучен спектр устойчивости грибов рода Candida к антибиотикам наиболее часто используемых в клинической практике. Проанализирована общность действия различных антибиотиков на основе корреляционных связей. Установлено число мультирезистентных штаммов среди рассматриваемой группы клинических изолятов. А также выявлено, что наиболее эффективным антимикробным препаратом оказался клотримазол, а наименее эффективным - флуконазол. При этом для преодоления антибиотикорезистентности рекомендуется использовать сочетание клотримазол и амфотерицин В.

Ключевые слова: антибиотикорезистентность, грибковые инфекции мочевыводящих путей, грибы рода Candida.

\section{Введение.}

Наиболее распространенными грибковыми инфекциям, затрагивающими широкие возрастные группы населения, являются инфекции вызванные микроскопическими дрожжеподобными грибами рода Candida (в первую очередь - Candida albicans) $[1,2]$. Bce представители данного рода относятся к условнопатогенным микроорганизмам, входят в состав нормальной микрофлоры рта, влагалища и толстой кишки большинства здоровых людей. Candida spp. являются обитателями организма человека, они выявляются при посевах со слизистой оболочки полости рта и ЖКТ у 30-50 \% здоровых людей, и со 
слизистой оболочки гениталий у 20-30\% здоровых женщин [3, 4].

В случае ослабления защитных сил организма количество грибов увеличивается, они могут приобрести агрессивные свойства и явиться причиной развития болезни, вызвав воспаление. У детей кандиды чаще всего поражают полость рта, у женщин - влагалище и наружные половые органы.

Клинические проявления инфекции, обусловленной грибами рода Candida, имеют очень широкий спектр проявлений от локального поражения слизистых оболочек до распространенной диссеминации с мультиорганным поражением. Хотя грибы Candida рассматриваются как нормальная флора желудочно-кишечного и урогенитального тракта у человека, они имеют склонность к инвазии и, в случаях, когда создается дисбаланс в экологической нише, где эти микроорганизмы обычно существуют, могут вызывать заболевание.

Иммунный ответ организма является важным определяющим фактором характера инфекции, вызываемой грибами Candida. Наиболее безопасные типы инфекции характеризуются локальным разрастанием грибов на слизистой оболочке (орофарингеальный кандидоз, вагинит) в результате нарушения нормальной флоры. Более обширные и персистирующие процессы с поражением слизистых оболочек встречаются у лиц с недостаточностью Т-клеточного звена иммунитета, например, при СПИДе.

Инвазивные очаговые поражения, такие как пиелонефриты, эндокардиты и менингиты, наиболее часто являются следствием гематогенного распространения возбудителя, анатомические изменений или наличия устройств (например, протезов сердечных клапанов или шунтов ЦНС). У пациентов с нейтропенией или у тяжелых больных, находящихся в отделениях

интенсивной терапии, в случаях, когда грибы Candida попадают в кровоток, может развиться распространенная висцеральная диссеминация.

Основная цель терапии инфекций вызванных штаммами рода $\underline{\text { Candida }}$ заключается в достижении эффекта исчезновения клинических симптомов, поддержании местного иммунитета, а также поддержания баланса условно-патогенных микроорганизмов $[5,6]$.

Основной проблемой борьбы с грибами рода Candida является самостоятельное симптоматическое лечение грибковых заболеваний без предварительного лабораторного исследования, что, в свою очередь, приводит к росту числа антибиотикорезистентных штаммов бактерий, частота встречаемости которых коррелирует с интенсивностью использования антибиотических препаратов.

В связи с этим, целью настоящей работы стал анализ спектра антибиотикорезистентности бактериальных штаммов при инфекциях вызванных грибками рода Candida, выделенных у пациентов г. Оренбурга.

\section{Материалы и методы.}

Биологические субстраты были получены от пациентов многопрофильных клиник г. Оренбурга, посев с которых осуществляли на агар Никерсона (HiMedia, Индия), в результате чего было получено 177 изолятов грибов Candida spp. Определение чувствительности выделенных штаммов к антимикотикам осуществляли дискодиффузионным методом на среде Сабуро (НИЦФ, Россия). Были использованы диски (НИЦФ, Россия), содержащие амфотерицин В (40 мкг), нистатин (80 Ед), клотримазол $(10$ мкг $)$, итраконазол (10 мкг), флуконазол (40 мкг), кетоконазол (20 мкг). Критерии интерпретации результатов приведены в таблице 1.

Таблица 1

\section{Значения диаметров зон задержки роста при определении чувствительности дрожжеподобных} грибов Candida spp к антимикробным препаратам диск-диффузионным методом.

\begin{tabular}{|c|c|c|c|}
\hline Противогрибные препараты & \multicolumn{3}{|c|}{ Диаметр зон (в мм) подавления роста культур } \\
\cline { 2 - 4 } в диске & Устойчивых & Промежуточных & Чувствительных \\
\hline Амфотерицин В 40 мкг & $<14$ & - & $\geq 14$ \\
\hline Нистатин 80 ЕД & $<18$ & - & $\geq 18$ \\
\hline Клотримазол 10 мкг & $<12$ & - & $\geq 12$ \\
\hline Флуконазол 40 мкг & $\leq 19$ & $20-28$ & $\geq 29$ \\
\hline Итраконазол 10 мкг & $\leq 13$ & $14-18$ & $\geq 19$ \\
\hline Кетоконазол 20 мкг & $\leq 19$ & $20-25$ & $\geq 26$ \\
\hline
\end{tabular}

Полученные данные проанализированы с использованием пакета программ Microsoft Office и Statistica с расчетом средней арифметической и ошибки средней, а также нормированного отклонения, дисперсии и корреляционного анализа.

Результаты и обсуждение.

Оценка вариации чувствительности к антибиотикам. Установлено, что наиболее выраженные зоны подавления роста были характерны для кетоконазола, для которого зарегистрирован размах значений от 0 до 42 мм со средней величиной 24,9 $\pm 0,4$ мм (рисунок 1 ). Тем не менее, коэффициент вариации для данного препарата оказался одним из наиболее высоких и составил $41 \%$. Максимальный коэффициент вариации, равный $47 \%$ был получен для флуконазола, который оказался антимикотиком, формирующим одни из выраженных величин зоны подавлении роста, равной $23 \pm 0,4$ мм. С другой стороны, наименьшую эффективность по данному критерию продемонстрировали итраконазол и амфотерицин В, для которых данные величины 
составили $16,8 \pm 0,3$ мм и $16,9 \pm 0,3$ мм, соответственно. Тем не менее, величина зоны подавления роста не отражает реальную действительность эффективности препарата, например, в случае с кетоконазолом штамм считается чувствительным при наличии зоны подавления более 26 мм, а для итраконазола это только 18 мм.

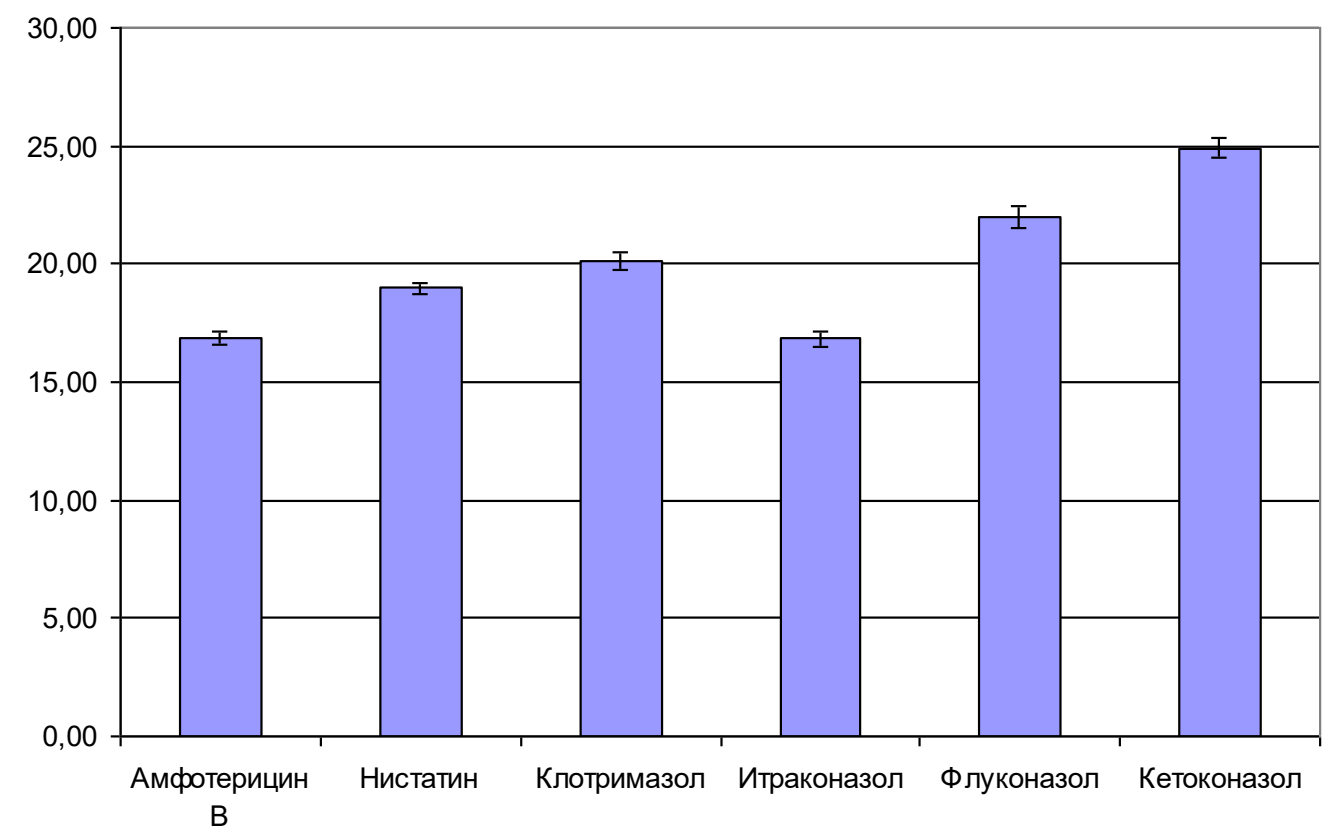

Рисунок 1 - Средние величинь диаметров зон подавления для Candida spp.

В связи с этим, более адекватной оценкой является расчет числа чувствительных, умеренночувствительных и резистентных штаммов согласно рекомендуемым величинам для каждого из препаратов.

Оценка спектра устойчивости к антибиотикам. Установлено, что наибольшая доля среди проанализированных штаммов Candida spp. устойчива к воздействию нистатина $(27,11 \%)$ и амфотерицина В $(26,55 \%)$, а наименьшая доля устойчивых штаммов зарегистрирована в отношении клотримазола (таблица 2). В целом, ряд антимикотикорезистенстности выделенных культур Candida к использованным в работе препаратам можно выстроить по мере убывания данного показателя следующим образом: нистатин
$>$ амфотерицин В > флуконазол > итраконазол > кетоконазол > клотримазол.

Тем не менее, в отношении некоторых препаратов штаммы демонстрировали умеренную чувствительность, что свидетельствует о недостаточной эффективности их действия. В частности, 59,88 \% штаммов были умеренно чувствительны к флуконазолу, 34,46 \% - к итраконазолу и 25,98 \% - к кетоконазолу. В связи с этим, более адекватным в практическом применении будет ряд чувствительности культур к используемым препаратам, который по мере возрастания данного показателя выглядит следующим образом: флуконазол $>$ итраконазол $>$ нистатин $>$ кетоконазол $>$ амфотерицин $\mathrm{B}>$ клотримазол.

Таблица 2

Число чувствительных (S), умеренно устойчивых (I) и устойчивых (R) среди полученных изолятов.

\begin{tabular}{|c|c|c|c|}
\hline Антимикотик & $\mathrm{S}$ & $\mathrm{I}$ & $\mathrm{R}$ \\
\hline Амфотерицин В & 121 & 9 & 47 \\
\hline Нистатин & 101 & 28 & 48 \\
\hline Клотримазол & 162 & 10 & 5 \\
\hline Итраконазол & 79 & 61 & 37 \\
\hline Флуконазол & 27 & 106 & 44 \\
\hline Кетоконазол & 104 & 46 & 27 \\
\hline
\end{tabular}

Анализ сочетанности

действия

антимикотиков. Нами было проанализировано наличие однотипности воздействия различных антимикробных препаратов на один и тот же изолят кандид путем сопоставления ковариации их диаметров зон подавления роста. Наибольший уровень сочетанности используемых препаратов характерен для пар клотримазол и итраконазол $(\mathrm{r}=$ $0,49, \mathrm{P}<0,001)$, а также флуконазол и кетаконазол $(\mathrm{r}=0,44, \mathrm{P}<0,001)$. К тому же указанные две пары антимикотиков коррелируют между собой, формируя перекрестные пары, но с меньшими 
коэффициентами корреляции, образуя тем самым «плеяду». Данные препараты относятся к группе противогрибковых антибиотиков - азолов и имеют общий механизм действия. Азолы нарушают синтез эргостерола - основного структурного компонента клеточной мембраны грибов. Эффект связан с ингибированием цитохром-Р450-зависимых ферментов, в том числе 14-альфа-деметилазы (стерол-14-деметилаза), катализирующей реакцию превращения ланостерола в эргостерол, что и приводит к нарушению синтеза эргостерола клеточной мембраны грибов [7].

C другой стороны высокий уровень сочетанности $(\mathrm{r}=0,31, \mathrm{P}<0,001)$ используемых антимикотических препаратов характерен для пары амфотерицин В - нистатин, относящихся к группе противогрибковых препаратов - полиенов, что связано с однотипностью их воздействия обусловленное связыванием препарата с эргостеролом мембраны бактерий, что ведет к нарушению ее целостности, потере клеточных макромолекул, ионов и к лизису клетки [8].

Анализ числа полирезистентных штаммов. В дальнейшем нами была проведена итоговая оценка числа чувствительных штаммов (S), устойчивых к одному или двум антимикотикам (R12), устойчивых к трем или четырем антимикотикам (R34) и полирезистентных штаммов (MDR) (рисунок 2).

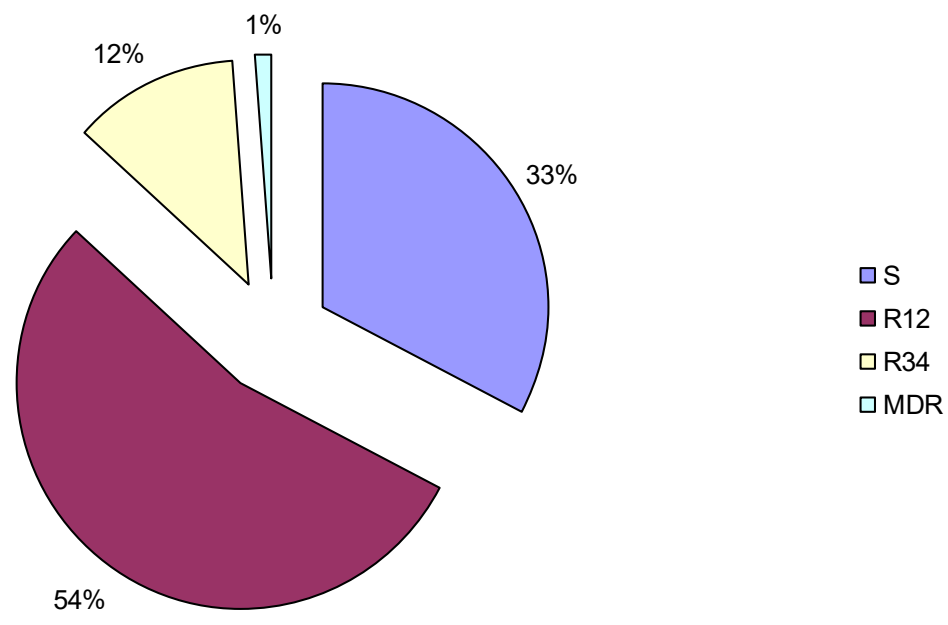

Рисунок 2 - Распределение чувствительных (S), устойчивых к одному или двум антимикотикам (R12), yстойчивых к трем или четырем антимикотикам (R34) $u$ полирезистентных штаммов (MDR) среди изученных изолятов.

В группе выделенных штаммов Candida значительная доля изолятов является устойчивой к одному или двум антимикотикам (около 54 \%), около $12 \%$ составляли штаммы, устойчивые к трем или четырем антибиотикам, а число мультирезистентных штаммов было не значительно и составляло $1 \%$ от общего числа и проявляющих невосприимчивость к пяти или шести видам антимикробных препаратов.

\section{Заключение.}

Оценивая общее число всех штаммов, проявляющих устойчивость к действию использованных антимикотиков, стоит отметить, что наибольшее число таковых выявлено в отношении амфотерицина В, а с другой стороны, наибольшую степень эффективности проявил клотримазол. В целом это позволило выстроить ряд эффективности антимикробных препаратов по мере убывания их способности ингибировать рост грибков рода Candida: клотримазол $>$ амфотерицин $\mathrm{B}>$ кетоконазол $>$ нистатин $>$ итраконазол $>$ флуконазол. В качестве рекомендации для преодоления антимикотикорезистентности рекомендуется использовать сочетание клотримазол и амфотерицин В.

\section{Список использованных источников}

1 Сергеев, А.Ю. Кандидоз : природа инфекции, механизмы агрессии и защиты, диагностика и лечение / А.Ю. Сергеев, Ю.В. Сергее. - Москва : Триада-Х, 2016. - 472 с.

2 Федорова, Н.И. Исследование чувствительности к противогрибковым препаратам клинических штаммов Candida parapsilosis, выделенных в стационарах разного профиля / Н.И. Федорова, А.Б. Кулько / Вестник Национального медико-хирургического Центра им. Н.И. Пирогова - 2015, т. 10, № 4 - с. 69 - 71 .

3 Веселов, А.В. Эпидемиология возбудителей кандидозов и их чувствительность к азолам : результаты исследования ARTEMIS Disk в России / A.В. Веселов, И.Г. Мултых, Г.А. Клясова / Клиническая микробиология и антимикробная химиотерапия - 2015. т. 7. № 1. с. 68-76.

4 Саттон, Д Определитель патогенных и условно патогенных грибов : учебное пособие / Д. Саттон, А. Фотергилл, М. Ринальди. - Москва : Мир. - 2012. -468 с.

5 Сергеев, А.Ю. Грибковые инфекции : руководство для врачей / А.Ю. Сергеев, Ю.В. Сергее. - Москва : Бином, 2015. - 480 с.

6 Clerihew, L. Candida parapsilosis infection in very low birth weight infants / L. Clerihew, T.L. 
Lamagni, P. Brocklehurst. - Arch Dis Child Fetal Neonatal Ed, 2007. - Vol. 92. - P. 127 -129.

7 Новикова, В. В. Анализ видового состава и чувствительности клинических изолятов Candida spp. к современным антимикотикам / В.В. Новиков,
С.Г. Езов, А.И. Селиванова. - Медицинский альманах - 2017, № 2 - с. 138 - 141

8 Жорж, О.Н., Роль Candida spp .в формировании патологии шейки матки / О.Н. Жорж, А.К. Мирзабалаева / Проблемы медицинской микологии. 2016. Т. 13. № 1. с. 35-38.

\title{
ПРОВОСПАЛИТЕЛЬНЫЕ ЦИТОКИНЫ ПРИ ГИПОКСИЧЕСКИ-ИШЕМИЧЕСКОМ ПОРАЖЕНИИ ЦНС У НОВОРОЖДЕННЫХ
}

\author{
Кузьмина Екатерина Сергеевна \\ ассистент кафедры иммунологии с курсом \\ ДПО Ставропольского государственного медицинского университета \\ г.Ставрополь \\ Агранович Олег Виленович \\ доктор медицинских наук, профессор, \\ заведуюший кафедрой неврологии и медицинской реабилитации \\ Ставропольского государственного медииинского университета \\ г..Ставрополь \\ Слобидкер Дарья Сергеевна \\ заочный аспирант кафедры иммунологии с курсом ДПО \\ Ставропольского государственного медииинского университета \\ г.Ставрополь \\ Обедин Александр Николаевич \\ доктор медииинских наук, доиент, \\ заведующчй кафедрой анестезиологии, реаниматологии и скорой медицинской помощчи \\ Ставропольского государственного медииинского университета \\ г.Ставрополь \\ PRO-INFLAMMATORY CYTOKINES IN HYPOXIC-ISCHEMIC ENCEPHALOPATHY IN \\ DOI: $\underline{10.31618 / \text { nas.2413-5291.2019.1.50.108 }}$ \\ NEWBORNS
}

Kuzmina Ekaterina Sergeevna Assistant of the Department of Immunology with a course of continuing professional education of Stavropol State Medical University Stavropol

Agranovich Oleg Vilenovich Doctor of Medical Sciences, Professor, Head of the Department of Neurology and Medical Rehabilitation of Stavropol State Medical University Stavropol

Slobidker Darya Sergeevna correspondence postgraduate student of the Department of Immunology with a course of continuing education of Stavropol State Medical University Stavropol

Obedin Alexander Doctor of Medical Sciences, Assistant Professor, Head of the Department of Anesthesiology, Intensive Care and Emergency Medicine of Stavropol State Medical University Stavropol

\section{Аннотация}

В современных исследованиях показана вовлеченность иммунных механизмов в патогенез перинатальных поражений ЦНС. Известно, что нейроглиальная активация сопровождается увеличением синтеза про- и противовоспалительных цитокинов, что приводит к лейкоцитарной инфильтрации ткани мозга.

Целью работы явилось определение уровня провоспалительных цитокинов (IL-6, IL-8, IL-17) в сыворотке крови доношенных новорожденных детей с церебральной ишемией II-III степени. В исследовании представлен анализ 26 пациентов с церебральной ишемией, проведена оценка их объективного статуса, лабораторных и инструментальных методов обследования. Выявлено статистически значимое увеличение уровня IL-6, IL-8, IL-17 по сравнению с контрольной группой, что свидетельствует об их участии в патогенезе церебральной ишемии. 